\title{
PERAN SALES PROMOTION DAN BRAND EQUITY DALAM MEMENGARUHI RE-PURCHASE INTENTION PRODUK FASHION DI MARKETPLACE
}

\author{
Yudhistira Rangga Paksi \\ Universitas Negeri Surabaya \\ yudhistira.17080574139@mhs.unesa.ac.id \\ Tias Andarini Indarwati \\ Universitas Negeri Surabaya \\ tiasindarwati@unesa.ac.id
}

\begin{abstract}
Indonesia's e-commerce growth in 2020 has increased quite a lot compared to 2019. Fashion is rising and safe to shop online at Indonesian e-commerce and Shopee as one of the largest E-commerce in Indonesia. Erigo, as a local Indonesian brand, competes with competitors to get customers repurchase intentions. The article examines the impact of sales promotion and brand equity on customer intention to repurchase Erigo local brand products by studying the Shopee marketplace. The sample of this research is respondents who have purchased Erigo products at Shopee. This primary data was collected by questionnaire and observation. Data analysis with multiple linear regression and sample used was 121 respondents. The sampling method used nonprobability sampling, and the sampling technique was judgmental sampling. The results showed that Sales Promotion and Brand Equity had a significant influence on the repurchase intention of Erigo products. This study recommends Erigo to maintain brand equity. Erigo also must keep their unique promotions, such as low prices at the end of the month and get free items for the purchase. Erigo can also use the findings for its brand evaluation.
\end{abstract}

Keywords: brand equity; e-commerce; re-purchase intention; sales promotion.

\section{PENDAHULUAN}

Di era industri 4.0, komunikasi dan teknologi informasi dapat membantu kehidupan dalam berbagai macam bidang, seperti elektronik, travelling, music dan termasuk dalam dunia industri fashion, sarana tersebut merupakan digital marketing (Nurdian, 2021). Pada peningkatan e-commerce di Indonesia pada tahun 2020 yang meningkat sangat tajam. Peningkatan pada pengguna smartphone yang terhubung pada 25 juta pengguna internet, hal ini memerjelas bahwa sangat penting visibilitas dari bisnis $e$ commerce di internet (Algustin, 2020).

Dari data e-commerce Indonesia, banyaknya pencarian informasi yang berkaitan dengan produk dan jasa yang mencapai angka $93 \%$. Pada usia 16 tahun ke atas, mereka yang melakukan pembelian produk atau jasa secara online mencapai angka $88 \%$ dan sementara $80 \%$ di antaranya menggunakan smartphone untuk melakukan akses pembelian online (Nurdian, 2021). Terjadi peningkatan yang signifikan dalam perilaku konsumen belanja ke online shop di Indonesia dari tahun 2018 sampai tahun 2019. Hal ini menunjukkan adanya perilaku dari berbelanja toko offline berpindah belanja ke online shop (Cipto, 2020).

Survei aktivitas pembelian berdasarkan barang di Indonesia tahun 2018 dan 2019, beberapa hal seperti makanan dan kebutuhan sehari-hari, perabotan rumah atau furniture, dan game atau hobby meningkat secara pesat seiring dengan mudahnya dalam proses pengiriman barang secara online. Dalam dunia fashion juga meningkat perlahan seiring amannya dalam pengiriman barang secara online (Nurdian, 2021). Promosi penjualan adalah indikator yang berpengaruh dalam dunia fashion dan penentu konsumen untuk memilih barang yang akan dipakai (Cipto, 2020).

Erigo merupakan salah satu brand fashion asal Indonesia yang mengutamakan kualitas dan style desain pada produk yang dirilis, yang telah berdiri sejak tahun 2013 yang pada awal merintis usaha dengan 
brand bernama "Selected and Co". Namun brand tersebut sama dengan nama brand lain, sehingga pada Juni 2013 diubah menjadi "Erigo. Erigo telah mengantongi beberapa penghargaan seperti Rekor Muri dalam penjualan kaos terbanyak via online dalam satu jam dengan berkolaborasi dengan brand lokal lainnya yaitu Thanksinsomnia dan Erigo juga telah mendapatkan rekor 4 bulan berturut-turut dalam Shopee Awards Brand terlaris kategori fashion (Nugraha, 2019).

Erigo menggunakan bentuk promosi penjualan yang aktif yaitu: online sale khusus di Shopee dan diskon yang termasuk di dalamnya pada event tour diberbagai kota, serta program diskon dan penawaran lain. Diskon dan pembagian kupon memengaruhi konsumen dalam membeli ulang di Shopee (Rosaliana, 2018). Diskon diadakan melalui media e-commerce Shopee secara periodic. Program diskon Erigo yang bekerja sama dengan Shopee lainnya yaitu diskon pada bulan tertentu seperti 11.11 atau 12.12 dan program gratis ongkir. Beberapa hal tersebut membuat konsumen mendapatkan keuntungan dan kesenangan dari promosi penjualan yang ditawarkan seperti kupon dan diskon (Rosaliana, 2018).

\section{Find Out E-commerce Competition in Indonesia}

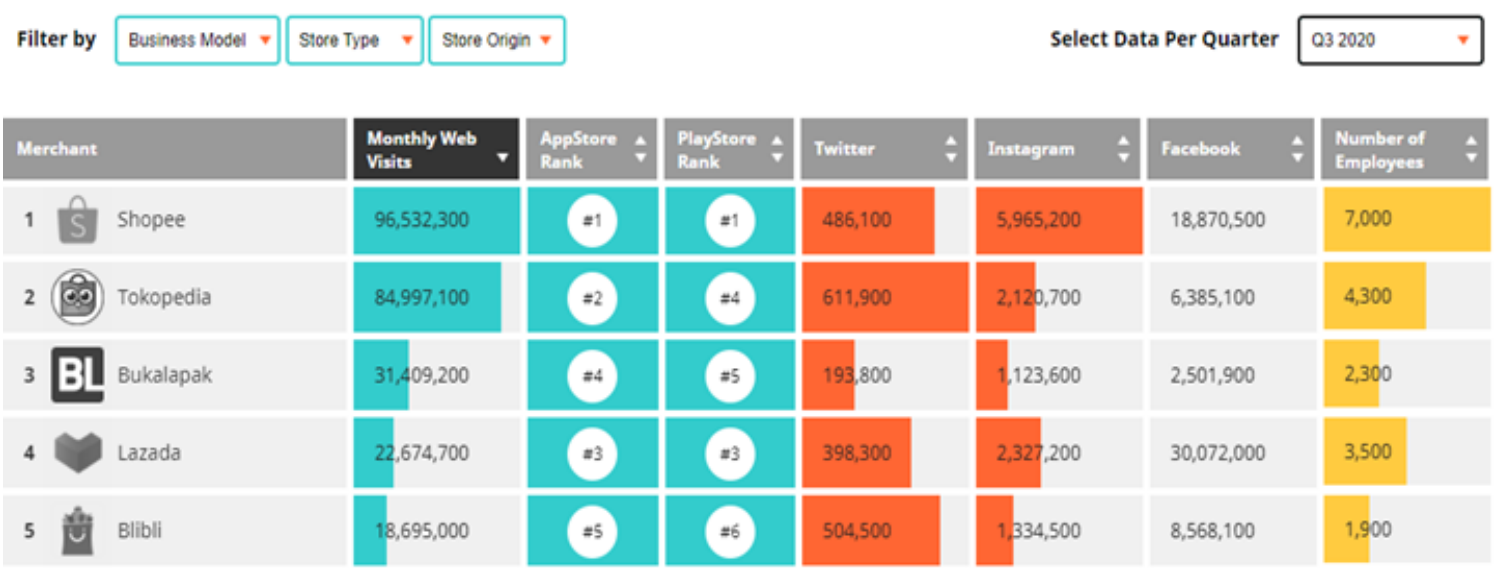

Sumber: (iPrice.co.id, 2021)

\section{Gambar 1. 5 E-COMMERCE PALING TERKENAL DI INDONESIA}

Gambar 1 menunjukkan fenomena yang ada saat ini yaitu minat beli ulang fashion brand lokal pada pembelian online di Shopee, karena pada kuartal 3, Shopee berhasil menjadi e-commerce pertama di Indonesia dengan pengguna atau member aktif bulanan terbanyak. Shopee menempati peringkat pertama yang disusul oleh Tokopedia dan Bukalapak. Shopee melakukan beberapa campaign dalam kuartal ini seperti cashback, free ongkir tanpa minimum order dan pemilihan brand ambassador dari para artis terkenal yang dekat dengan pengguna, dan hal ini bisa dijadikan bukti kekuatan Shopee untuk memegang dan mengakuisisi pasar di Indonesia. Maka, Shopee merupakan top marketplace ecommerce pada Q1 2020 sampai Q3 2020 (iPrice.co.id, 2021)/

Berdasarkan paparan dari latar belakang di atas, penelitian ini bertujuan untuk menganalisis promosi dari sales promotion dan brand equity yang memengaruhi re-purchase intention pada pembelian produk Erigo di marketplace Shopee.

\section{KAJIAN PUSTAKA DAN PENGEMBANGAN HIPOTESIS}

\section{Sales Promotion}

Promosi penjualan merupakan suatu kumpulan alat insentif yang diciptakan untuk merangsang pembelian agar terjadi lebih besar atau lebih cepat atas produk atau jasa tertentu, baik oleh konsumen maupun oleh pedagang yang sebagian besar dirancang untuk jangka pendek (Kotler, 2009). Promosi penjualan merupakan promosi yang digunakan untuk meningkatkan penjualan melalui potongan harga 
atau hadiah pada waktu tertentu terhadap barang-barang tertentu pula. Promosi pernjualan merupakan metode atau suatu cara yang digunakan oleh pelaku pemasaran untuk menarik minat calon pembeli untuk menjadi konsumen suatu produk (Sustina, 2003).

Klasifikasi jenis-jenis promosi menurut Cipto (2020), terdiri atas promosi konsumen (consumer promotion), promosi dagang (trade promotion), dan promosi bisnis dan tenaga penjualan (sales force promotion). Promosi penjualan ada beberapa dimensi, yaitu: sampel, kupon, diskon, rabat (cashback), premi (suatu barang yng ditawarkan dengan harga lebih rendah bahkan gratis sebagai suatu bentuk insentif dari pembelian produk tertentu), hadiah, kontes, dan promosi terikat (Rosaliana, 2018).

\section{Brand Equity}

Brand equity yang menjelaskan mengenai suatu nilai tambah yang diberikan dalam produk atau jasa. ekuitas merek dapat terlihat dalam bagaimana pola pikir konsumen, yang berhubungan dengan merek dan juga pangsa pasar, harga, dan profitabilitas yang dimana diberikan merek bagi perusahaan (Otero, 2018). Ekuitas merek adalah serangkaian aset merek yang terkait dengan sebuah merek tertentu, nama dan sebuah simbol, yang menambah atau mengurangi nilai tertentu yang diberikan kepada sebuah produk atau jasa kepada pelanggan dari perusahaan tersebut dan perusahaan itu sendiri (Tjiptono, 2011).

Ada beberapa dimensi dalam brand equity, yaitu: (1) brand awareness adalah kemampuan dan cara dari konsumen untuk mengenali bahwa sebuah merk yang merupakan kategori dari produuk tertentu; (2) perceived quality yaitu bagian dari penilaian konsumen atas keunggulan dan superioritas pada produk secara keseluruhan, sehingga perceived quality mendasari pada evaluasi subjektif yang dilakukan konsumen terhadap kualitas produk yang mereka beli; (3) brand associations yaitu memori atau ingatan yang terkait dalam merek tersebut, asosiasi merek memiliki tingkat kekuatan tersendiri dan semakin tinggi dengan meningkatnya pengalaman konsumen dalam mengonsumsi dengan merek spesifik; (4) brand loyalty yaitu keterikatan yang dimiliki pelanggan pada sebuah merek (Tjiptono, 2011).

\section{Re-Purchase Intention}

Repurchase intention merupakan sebuah proses mengambil keputusan yang diambil konsumen sesudah pembelian atas produk tersebut (Gautam, 2018). Ketika seorang konsumen mempunyai respons yang sangat positif atas tindakan pembelian masa lalu, dari hal ini akan terjadi penguatan dari seorang konsumen, dengan pemikiran yang positif atas apa yang dia terima dan memungkinkan dari individu untuk melakukan mengulang pembelian (Sustina, 2003). Repurchase intention adalah suatu tindakan dari konsumen dan memiliki komitmen yang terbentuk setelah konsumen melaakukan pembelian suatu produk atau jasa tertentu. Tiga faktor yang berdampak pada minat seseorang untuk melakukan niat membeli kembali yaitu faktor psikologis, faktor pribadi, dan faktor Sosial (Kotler, 2009).

Repurchase intention dapat diidentifikasi melalui beberapa indikator sebagai berikut: (1) minat transaksional, bahwa konsumen berniat untuk melakukan pembelian dari suatu produk tertentu. (2) minat referensial, bahwa minat konsumen ingin memberikan sebuah referensi dan cenderung merekomendasikan suatu produk tertentu kepada konsumen yang lain. (3) minat preferensial, adalah perilaku konsumen memliki niat atau berniat menggambarkan perilaku konsumen yang memiliki preferensi paling utama pada sebuah produk, preferensi ini dapat diubah apabila sesuatu yang terjadi dengan product sesuai dengan preferensinya. (4) minat eksploratif, adalah konsumen berniat untuk suatu minat dapat digambarkan perilaku konsumen yang mencari informasi lebih mengenai produk yang telat diminatinya dan menggali informasi untuk mendukung sifat yang positif dari produk yang sama (Samaraweera, 2016).

\section{Hubungan antar Variabel}

Sales promotion berpengaruh terhadap minat pembelian uang karena kesenangan dan keuntungan yang telah didapatkan oleh konsumen pada pembelian sebelumnya (Rosaliana, 2018). Promosi penjualan kupon di Shopee memiliki pengaruh signifikan terhadap minat beli kembali. Artinya promosi penjualan kupon yang masih memiliki pengaruh positif terhadap minat beli kembali (Adelia, 2018). Oleh karena 
Yudhistira Rangga Paksi \& Tias Andarini Indarwati. Peran Sales Promotion dan Brand Equity dalam Memengaruhi Re-purchase Intention Produk Fashion di Marketplace

itu, terdapat pengaruh online promotion terhadap repurchase intentions. Promosi penjualan berpengaruh secara signifikan secara langsung terhadap minat pembelian ulang pada konsumen di marketplace e-commerce Shopee (Permana, 2018).

H1: Adanya pengaruh positif antara sales promotion dengan re-purchase intention.

Sales promotion berpengaruh secara signifikan terhadap minat beli ulang. Sales promotion akan mendorong konsumen untuk melakukan pembelian ulang dikarenakan keuntungan dan kepuasan yang telah didapatkan konsumen pada pembelian sebelumnya (Rosaliana, 2018). Terdapat pengaruh signifikan sales promotion terhadap repurchase intention (Cipto, 2020)

H2: Adanya pengaruh positif antara brand equity dengan re-purchase intention.

Indikator yang digunakan adalah brand equity secara positif terkait dengan niat membeli kembali konsumen. Karenanya, merek dengan ekuitas yang lebih tinggi biasanya menghasilkan niat beli yang lebih besar (Chang, 2017). Persepsi ekuitas merek berpengaruh positif terhadap minat beli (Algustin, 2020)

Model penelitian disajikan pada Gambar 2.

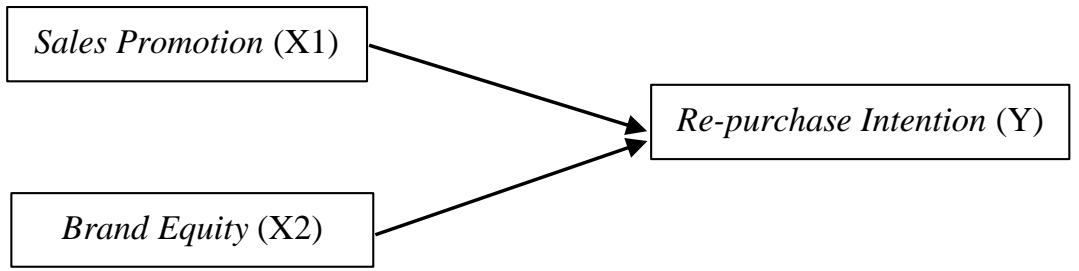

Gambar 2. MODEL PENELITIAN

\section{METODE PENELITIAN}

Penelitian ini merupakan jenis penelitian kausalitas yang mencari pengaruh antara sales promotion dan brand equity terhadap re-purchase intention. Responden dalam penelitian ini adalah pengguna internet yang bertranksaksi di shopee, tentunya dengan akun yang sudah memfollow akun Erigo di Shopee. Usia responden adalah 15-30 tahun. Metode pengambilan sampel yang digunakan adalah nonprobability sampling dengan teknik pengambilan sampel adalah judgemental sampling. Penyebaran angket menggunakan google form dan dilakukan secara online. Pelaksanaannya dapat diakses oleh siapa saja yang termasuk ke dalam kriteria responden. Angket dapat diakses melalui media sosial seperti whatsapp, instagram dan facebook. Pernyataan-pernyataan yang diberikan telah divalidasi oleh expert pemasaran sehingga dihasilkan 18 butir pernyataan. Bagian pertama angket merupakan pertanyaan yang digunakan untuk memfilter responden agar sesuai dengan karakteristik responden yang diharapkan. Bagian kedua merupakan pernyataan-pernyataan untuk mengukur variabel penelitian dengan menggunakan skala Likert. Regresi linier berganda digunakan untuk menganalisis data. Software yang digunakan yaitu IBM SPSS Statistics 26.0.

\section{HASIL DAN PEMBAHASAN}

\section{Karakteristik Responden}

Berdasarkan hasil penelitian data yang terkumpul dari 121 responden yang telah berpartisipasi dalam penelitian dapat diketahui bahwa responden dengan jenis kelamin laki-laki dan perempuan memiliki jumlah yang jauh berbeda. Hasil responden dengan jenis kelamin pria sebanyak 43 orang $(35,54 \%)$. Sedangkan hasil perolehan dari jenis kelamin wanita sebanyak 78 orang $(64,46 \%)$. Berdasarkan karakteristik usia 17-22 tahun dengan jumlah 104 orang (85,95\%), usia 23-28 tahun dengan jumlah 15 $(12,40 \%)$, dan usia 29 ke atas sebanyak 2 orang $(1,65 \%)$. Hal tersebut menunjukkan bahwa sebagian besar responden dalam penelitian ini berusia 17-22 tahun. Pada penelitian ini pendidikan terakhir dari responden adalah SMA 95 orang $(78,51 \%)$, Diploma 2 orang $(1,65 \%)$, Sarjana 22 orang $(18,18 \%)$, dan 
lainnya 2 orang $(1,65 \%)$. Hal tersebut menunjukkan bahwa sebagian besar pada penelitian ini adalah menempuh pendidikan terakhir SMA. Pada penelitian ini sebanyak 94 orang $(77,69 \%)$ pekerjaan mereka adalah pelajar/mahasiswa, 3 orang $(2,48 \%)$ adalah PNS, 14 orang $(11,57 \%)$ dengan pekerjaan pegawai swasta, 5 orang $(4,13 \%)$ tidak bekerja, 5 orang $(4,13 \%)$ lainnya. Hal ini menunjukkan pada penelitian ini sebagain responden pekerjaannya adalah pelajar/mahasiswa. Pada penelitian ini yang memiliki peghasilan < Rp1.000.000 sejumlah 60 orang (43,5\%), penghasilan Rp1.000.000Rp3.000.000 sebanyak 41 orang (33,06\%), penghasilan Rp3.000.001-Rp5.000.000 sebanyak 9 orang $(28,93 \%)$, penghasilan Rp5.000.001-Rp7.000.000 sebanyak 4 orang (1,65\%), dan penghasilan $>$ Rp7.000.000 sebanyak 7 orang $(4,96 \%)$. Dari hasil tersebut menunjukkan bahwa sebagian besar responden dalam penelitian ini berpenghasilan $<\mathrm{Rp} 1.000 .000$. Berdasarkan karakteristiknya, mayoritas wanita yang memiliki rentang usia 17-22 tahun dengan status sebagai pelajar/ mahasiswa. Apabila dikaitkan dengan profil responden tersebut, responden bergantung pada kecanggihan teknologi dan fitur yang terdapat pada e-commerce untuk memberikan informasi kepada mereka seperti diskon, kupon, dan hal update mengenai produk Erigo di Shopee. Hal ini mendasari acuan untuk membeli kembali konsumen.

Tabel 1.

\section{KARAKTERISTIK RESPONDEN}

\begin{tabular}{llcc}
\hline & Karakteristik Responden & Jumlah & Persentase (\%) \\
\hline Usia & 17-22 Tahun & 104 & $85,95 \%$ \\
& 23-28 Tahun & 15 & $12,40 \%$ \\
\multirow{3}{*}{ Jenis Kelamin } & 29 Tahun & 2 & $1,65 \%$ \\
Pendidikan Terakhir & Pria & 43 & $35,54 \%$ \\
& Wanita & 78 & $64,46 \%$ \\
& SMA & 95 & $78,51 \%$ \\
& Diploma & 2 & $1,65 \%$ \\
Pekerjaan & Sarjana & 22 & $18,18 \%$ \\
& Lainnya & 2 & $1,65 \%$ \\
& Pelajar/ Mahasiswa & 94 & $77,69 \%$ \\
& PNS & 3 & $2,48 \%$ \\
& Pegawai Swasta & 14 & $11,57 \%$ \\
& Tidak Bekerja & 5 & $4,13 \%$ \\
& Lainnya & 5 & $4,13 \%$ \\
& Kurang dari Rp1.000.000 & 60 & $43,5 \%$ \\
& Rp1.000.001-Rp3.000.000 & 41 & $33,06 \%$ \\
& Rp3.000.001-Rp5.000.000 & 9 & $28,93 \%$ \\
& Rp5.000.001-Rp7.000.000 & 4 & $1,65 \%$ \\
& Lebih dari Rp7.000.000 & 7 & $4,96 \%$ \\
\hline
\end{tabular}

Sumber: Data diolah (2020)

\section{Uji Validitas dan Reliabilitas}

Uji validitas telah dilakukan dan didapatkan hasil yang menunjukkan bahwa seluruh item dapat dijadikan sebagai alat ukur sebab seluruh item dinyatakan valid. Validitas item dapat dilihat dari nilai $r$ hitung > r tabel sebesar 0,3. Selanjutnya pada uji reliabilitas, nilai Cronbach Alpha pada variabel sales promotion sebesar 0,910, brand equity sebanyak 0,911. Nilai Cronbach Alpha tersebut menunjukkan bahwa seluruh item yang digunakan pada penelitian ini reliabel. Hasil perhitungan dari setiap variabel dikatakan reliable jika nilai Cronbach Alpha> 0,70 (Ghazali, 2016: 47-48).

\section{Uji Asumsi Klasik}

Pada penelitian ini data yang terkumpul dianalisis menggunakan regresi linear berganda, sebelumnya dilakukan uji normalitas untuk memastikan bahwa variabel berdistribusi normal. Uji normalitas menggunakan one-sample kolmogorov-smirnov test mendapatkan hasil nilai sig. (2-tailed) adalah 
Yudhistira Rangga Paksi \& Tias Andarini Indarwati. Peran Sales Promotion dan Brand Equity dalam Memengaruhi Re-purchase Intention Produk Fashion di Marketplace

0.210, melebihi 0.05 sehingga data menghasilkan distribusi normal, di mana signifikansi di atas taraf yang memenuhi hipotesis normalitas.

Uji multikolinieritas dilakukan dalam mengetahui hubungan antar variabel dengan melihat nilai VIF (Variance Inflation Factor) dan nilai tolerance yang dihasilkan. Data terbebas dari multikolinieritas apabila nilai VIF kurang dari 10 dan nilai tolerance harus lebih dari 0.01 . Nilai VIF sales promotion dan brand equity 1,430. Hasil uji multikolonieritas memenuhi asumsi multikolonieritas.

Uji Heteroskesdasitas dilihat dari nilai sig.(2-tailed) pada masing-masing variabel lebih besar dari 0,05, sales promotion nilai signifikansi sebesar $0,236>0,05$ dan brand equity sebesar $0,411>0,05$. Hasil dari uji heteroskesdasitas menunjukkan bahwa data telah memenuhi asumsi uji heteroskesdasitas.

\section{Uji Regresi Linier Berganda}

Tabel 2.

UJI HIPOTESIS

\begin{tabular}{llll}
\hline \multicolumn{1}{c}{ Variabel } & Koefisien Regresi & Uji T & Signifikan \\
\hline (Constant) & $-1,757$ & -1.392 & 0.167 \\
Sales Promotion & 0.127 & 2,119 & 0.036 \\
Brand Equity & 0.268 & 7,821 & 0.000 \\
\hline Sun
\end{tabular}

Sumber: Data diolah (2020)

$\mathrm{Y}=-1.757+0,127 \mathrm{X} 1+0,268 \mathrm{X} 2$.

Hasil analisis regresi linier berganda diperoleh persamaan regresi pada rumus (1). Dari hasil persamaan (1) dapat diinterpretasikan bahwa nilai kontsanta sebesar -1,757 dapat diartikan adanya tanda negatif pada konstanta menunjukkan apabila tidak terdapat variabel sales promotion dan brand equity maka niat beli ulang tidak terjadi pada produk Erigo. Niat beli ulang produk Erigo di Shopee yang dilakukan pelanggan tidak akan terjadi tanpa adanya faktor promosi penjualan dan brand equity. Nilai koefisien variabel promosi penjualan sebesar 0,127 , artinya apabila promosi penjualan yang diterima responden tentang niat beli ulang produk Erigo di Shopee semakin banyak, maka niat beli ulang responden akan semakin meningkat untuk membeli produk Erigo di Shopee. Nilai koefisien variabel brand equity sebesar 0,268. Artinya, semakin baik ekuitas merek yang dimiliki Erigo, seperti logo, desain produk, dan kualitas produk semakin meningkat, maka meningkatkan niat beli ulang responden.

\section{Hasil Uji Hipotesis}

Pada Tabel 2, dapat dijelaskan bahwa hasil analisis regresi linier berganda hipotesis pertama (H1) menunjukkan nilai thitung untuk variabel sales promotion 2,119 , hipotesis kedua (H2) yaitu variabel brand equity yang menunjukkan hasil dengan nilai sebesar 7,821. Kedua variabel independen memiliki nilai signifikansi lebih kecil dari 0,05, sehingga $\mathrm{H} 0$ ditolak sedangkan $\mathrm{H} 1$ dan $\mathrm{H} 2$ diterima. Hal ini membuktikan adanya pengaruh sales promotion dan brand equity terhadap niat beli ulang.

Tabel 3.

HASIL UJI F

\begin{tabular}{lrrrrl}
\hline Model & $\begin{array}{l}\text { Sum of } \\
\text { Square }\end{array}$ & \multicolumn{1}{c}{ df } & Mean Square & \multicolumn{1}{c}{ F } & \multicolumn{1}{c}{ Sig. } \\
\hline Regression & 304,302 & 2 & 152,151 & 59,939 & $0,000^{\mathrm{b}}$ \\
Residual & 299,533 & 118 & 2,538 & & \\
Total & 603,835 & 120 & & & \\
\hline
\end{tabular}

Sumber: Data diolah (2020)

Hasil uji F pada Tabel 3 menunjukkan nilai signifikansi 0,000, kurang dari 0,05. Hal ini menunjukkan bahwa, pengujian untuk model regresi linier berganda pada variabel sales promotion dan brand equity terhadap repurchase intention dinyatakan layak atau baik. 
Nilai Adjusted $R$ Square untuk variabel sales promotion dan brand equity terhadap variabel repurchase intention sebesar 0,481 atau sebesar $48,1 \%$. Artinya sales promotion dan brand equity memiliki pengaruh terhadap repurchase intention sebesar $48,1 \%$ dan sisanya dipengaruhi oleh variabel lain yang tidak termasuk dalam penelitian ini. Pada penelitian ini, brand equity menjadi variabel yang memiliki pengaruh paling besar terhadap repurchase intention.

\section{Pengaruh Sales Promotion terhadap Re-Purchase Intention}

Promosi penjualan adalah kegiatan yang dilakukan guna memberi informasi, membujuk, dan mengembalikan ingatan konsumen baik secara langsung ataupun tidak terkait suatu produk atau jasa atas merek yang dijual, selain itu juga sebagai salah satu unsur dari promotional mix, yaitu kumpulan dari alat intensif yang diciptakan untuk merangsang pembeli agar terjadi lebih cepat atau lebih besar atas produk atau jasa tertentu, baik oleh konsumen maupun perdagangan yang sebagian besar dirancang untuk jangka pendek (Kotler, 2009).

Hasil penelitian menunjukkan bahwa sales promotion memiliki pengaruh positif terhadap re-purchase intention. Indikator yang digunakan adalah promosi penjualan dan hasil penelitian tersebut, dapat diketahui bahwa sales promotion berpengaruh terhadap minat beli ulang. Rosaliana (2018) menyatakan promosi penjualan kupon di Shopee berpengaruh signifikan terhadap minat beli kembali, yang artinya promosi penjualan kupon masih berpengaruh positif terhadap minat beli kembali. Cipto (2020) menyatakan bahwa promosi penjualan memiliki pengaruh signifikan secara langsung terhadap minat pembelian ulang di marketplace e-commerce Shopee. Terdapat pengaruh positif online promotion terhadap pembelian ulang pada konsumen. Hal seperti ini membuat konsumen mendapatkan keuntungan dan kesenangan dari promosi penjualan yang ditawarkan seperti kupon dan diskon (Rosaliana, 2018). Promosi penjualan adalah indikator yang berpengaruh dalam dunia fashion dan penentu konsumen untuk memilih barang yang akan dipakai (Cipto, 2020).

Responden yang mendominasi pada penelitian ini usia 17-29 tahun dengan jenis kelamin perempuan, memiliki pekerjaan sebagai pelajar/ mahasiswa, serta pengeluaran kurang dari Rp1.000.000, di mana kategori ini responden secara kemampuan ramah dengan dunia digital dan memiliki lebih banyak waktu luang sehingga lebih banyak menghabiskan waktu dengan internet atau dunia digital. Pada usia tersebut, ingin mengetahui banyak hal baru sehinggan aktif dalam berinteraksi dengan satu sama lain. Hadirnya kecanggihan perangkat teknologi saat ini untuk mendapatkan referensi pilihan produk dari brand lokal atau promo dari layanan e-commerce, pada usia tersebut mendapatkan informasi dengan melihat pada laman beranda brand pada e-commerce, hal tersebut digunakan sebagai acuan calon pembeli. Selain itu sesuai dengan data responden yang didominasi perempuan yang berumur 17-29 tahun, e-commerce merupakan platform yang paling diminati kaum muda, dan hal ini selaras dengan survey dari (Nurdian, 2021), pada usia 16 tahun ke atas, mereka yang melakukan pembelian produk atau jasa secara online mayoritas menggunakan smartphone dalam melakukan akses pembelian online. Terjadi peningkatan sangat tajam dalam perilaku belanja ke online shop dari e-commerce di Indonesia pada sepanjang tahun 2019. Mayoritas responden juga memilih Erigo karena memiliki program diskon dengan Shopee dan Erigo memberikan diskon yang lebih besar dibanding produk brand lokal lain.

\section{Pengaruh Brand Equity terhadap Re-Purchase Intention}

Brand equity adalah nilai yang ditambahkan dan diberikan pada produk atau jasa (Kotler, 2009). Hasil responden yang mendominasi penelitian ini adalah pada rentang usia 19-29 tahun atau anak muda yang lebih cepat menerima berbagai informasi perkembangan merek yang ada saat ini. Dominasi karakteristik lain dari responden yaitu rata-rata berjenis kelamin wanita yang bekerja sebagai mahasiswa/pelajar sehingga memiliki banyak waktu luang dan memiliki gaya hidup yang suka berbelanja di e-commerce karena beberapa campaign yang dilakukan e-commerce Shopee seperti cashback, free ongkir tanpa minimum order memengaruhi niat beli ulang Kemudian dominasi responden memiliki pengeluaran kurang dari Rp1.000.000, hal ini sesuai dengan harga produk yang ditawarkan Erigo di mana harga yang ditawarkan relatif murah dari brand lokal lain. Hal tersebut akan menarik bagi konsumen dan membuat konsumen lebih mengingat suatu merek tersebut. 3 dimensi ekuitas merek berperan dalam pengambilan keputusan konsumen untuk membeli kembali, yang 
pertama itu brand awareness adalah kemampuan konsumen untuk mengenal sebuah merek dan mengingat sebuah merek tertentu atau yang sudah pernah dibeli, yang kedua perceived quality yaitu penilaian konsumen terhadap kualitas produk dari subyektif konsumen, yang ketiga adalah brand associations adalah memori atau ingatan yang terkait dalam merek tersebut. Asosiasi merek memiliki tingkat kekuatan tersendiri dan semakin tinggi dengan meningkatnya pengalaman konsumen dalam menkonsumsi dengan merek spesifik, dan yang keempat brand loyalty dimana konsumen sangat loyal dengan produk atau selalu membeli produk dari brand tersebut (Tjiptono, 2011).

Responden pada penelitian lebih familiar dengan produk Erigo dibanding produk brand lokal lain hal ini terlihat dari hasil item pernyataan terkait brand equity pada tingkat brand awareness. Responden juga mengingat logo dan nama produk Erigo, artinya responden telah mengetahui dengan baik tentang Erigo tanpa bertanya kepada orang lain. Pada penelitian ini responden selalu mengunjungi laman Erigo di Shopee setiap ada produk baru. Hal itu yang membuat inovasi dari Erigo yang selalu menghadirkan produk terbaru setiap bulannya Adanya paparan hasil pembahasan dan hasil penelitian menunjukkan bahwa terdapat pengaruh brand equity memiliki dampak signifikan terhadap niat membeli kembali. Indikator yang digunakan adalah brand equity secara positif terkait dengan niat membeli kembali konsumen. Karenanya, merek dengan ekuitas yang lebih tinggi biasanya menghasilkan niat beli yang lebih besar (Chang, 2020). Ekuitas merek sangat memengaruhi pandangan konsumen sehingga berdampak pada peningkatan atau penurunan nilai produk (Adelia, 2018). Ekuitas merek membuat pembeli merasa puas pada pembelian sebelumnya dan merencanakan pembelian yang akan datang (Otero, 2018).

\section{KESIMPULAN}

Kedua hipotesis dalam penelitian diterima, yaitu variabel sales promotion dan brand equity berpengaruh signifikan terhadap re-purchase intentions pada produk Erigo di marketplace Shopee. Pada penelitian ini sales promotion berpengaruh signifikan terhadap re-purchase intentions. Promosi penjualan yang dilakukan oleh Erigo di Shopee dapat dikatakan berhasil menarik calon konsumen yang akan membeli. Variabel brand equity berpengaruh signifikan terhadap niat beli ulang, karena merek dengan ekuitas yang lebih tinggi biasanya menghasilkan niat beli yang lebih besar

Dari hasil responden, Erigo menjadi pilihan utama para calon konsumen di antara brand lokal lain. Promosi penjualan yang dilakukan Erigo di Shopee seperti diskon, kupon gratis ongkir dan program cashback berhasil memengaruhi niat beli konsumen untuk membeli kembali. Erigo memberikan inovasi pada produk mereka yang melekat dengan istilah "Streetwear Style" untuk memengaruhi anak muda agar tertarik untuk membeli produk Erigo di Shopee. Sama halnya dengan seri produk jaket "Sukajan" yang dikeluarkan oleh Erigo. Strategi yang dilakukan Erigo pada brand equity berdampak sangat besar pada konsumen yang hendak niat membeli ulang produk Erigo. Karena dominasi dari respondeng mengetahui tentang kualitas produk Erigo dan kualitas produk Erigo sesuai dengan harapan konsumen. Hasil penelitian ini menunjukkan bahwa sales promotion dan brand equity memengaruhi niat beli ulang pada konsumen. Erigo perlu memberikan hal yang baru agar dapat menjangkau lebih banyak konsumen dan tetap loyal kepada brand Erigo. Apabila Erigo mengeluarkan seri lain dari jaket sukajan ataupun streetwear style, Erigo akan memberikan pengalaman pada konsumen agar tumbuh rasa puas dan memberikan dorongan pada niat konsumen untuk melakukan pembelian ulang pada lain waktu.

Penelitian selanjutnya dapat melibatkan variabel lifestyle untuk membeli produk tertentu Erigo, dan variabel demografis pengeluaran. Penelitian selanjutnya juga dapat menggunakan consumer group discussion untuk mengetahui lebih detail terkait produk tertentu tentang Erigo. Erigo dan Shopee juga erat kaitannya dengan long-term project.

\section{DAFTAR PUSTAKA}

Adelia, S. (2018). Pengaruh Online Promotion Terhadap Repurchase Intention Dengan Consumer Perception Sebagai Mediasi Pada Travel Online. Jurnal Manajemen Pemasaran, 12(2), 94-100. 
Algustin, W., \& Matoati, R. (2020). Pengaruh Ekuitas Merek terhadap Minat Beli Ulang Produk Emina Pada Generasi Z. Jurnal Bisnis dan Ekonomi, 27(1).1-12.

Bhatti, A. (2018). Sales promotion and price discount effect on consumer purchase intention with the moderating role of social media in Pakistan. International Journal of Business Management, 3(4), $50-58$.

Chang, A. Y. P. (2017). A study on the effects of sales promotion on consumer involvement and purchase intention in tourism industry. Eurasia Journal of Mathematics, Science and Technology Education. 13(12), 8323-8330.

Belch, G. E., \& Belch, M. A. (2004). Advertising and promotion: An integrated marketing communications perspective 6th. New York: McGraw-Hill.

Cipto, H., \& Erdiansyah, R. (2020). The Effect of Sales Promotion, Service Quality, Perceived Value on Repurchase (Case Study of Original Levis Store in Jakarta). In The 2nd Tarumanagara International Conference on the Applications of Social Sciences and Humanities (TICASH 2020) (pp. 197-201). Atlantis Press.

Engel. (1994). Perilaku Konsumen. Edisi keenam. Jilid 1. Jakarta: Binarupa Aksara.

Ferdinand, A.T., (2000), Manajemen Pemasaran: Sebuah Pendekatan Stratejik. Semarang: Badan Penerbit Universitas Diponegoro.

Gautam, D. K., \& Shrestha, S. K. (2018). Impact of Brand Equity on Purchase Intention of Smart Phones. Asia-Pacific Journal of Business, 9(1), 1-18.

Ghazali. 2016. Aplikasi Analisis Multivariete Dengan Program IBM SPSS 23 (Edisi 8). Cetakan ke VIII. Semarang: Badan Penerbit Universitas Diponegoro.

iprice.co.id. (2019). The Map of E-commerce in Indonesia. (https://iprice.co.id/insights/mapofecommerce/en/ diakses tanggal 14 Maret 2021)

Kotler, P. (2009). Manajemen Pemasaran. Jakarta: Erlangga.

Nugraha, Ricky. (2019). Erigo x Thanksinsomnia Cetak Rekor MURI Penjualan Kaos Terbanyak via Online dalam Sejam. (https://hai.grid.id/read/071895608/erigo-x-thanksinsomnia-cetak-rekormuri-penjualan-kaos-terbanyak-via-online-dalam-sejam diakses tanggal 28 April 2021)

Nurdian, Graha. (2021). E-Commerce Indonesia Tahun 2020. Era Digital Mendominasi. (http://grahanurdian.com/e-commerce-indonesia-tahun-2020/\#10- diakses tanggal 15 Maret 2021)

Otero, C., \& Wilson, G. P. (2018). Effects of brand love and brand equity on repurchase intentions of young consumers. International Review of Management and Marketing, 8(4), 7-13.

Permana, H., \& Djatmiko, T. (2018). Analisis pengaruh kualitas layanan elektronik (e-service quality) terhadap kepuasan pelanggan shopee di Bandung. Sosiohumanitas, 20(2), 64-78.

Rosaliana, F., \& Kusumawati, A. (2018). Pengaruh Sales Promotion Dan Kualitas Pelayanan Terhadap Kepuasan Konsumen Serta Dampaknya Pada Minat Pembelian Ulang (Survei pada Konsumen Jasa GrabCar di Kota Malang). Jurnal Administrasi Bisnis, 60(1), 139-148.

Samaraweera, G. C. (2016). Effect of consumer based brand equity on purchase intention of the crisis brand: moderating role of peer recommendation. IR South Eastern University.85-90 
Yudhistira Rangga Paksi \& Tias Andarini Indarwati. Peran Sales Promotion dan Brand Equity dalam Memengaruhi Re-purchase Intention Produk Fashion di Marketplace

Senthilnathan, S. (2012). The relationship of brand equity to purchase intention. IUP Journal of Marketing Management. XI(2). 7-26.

Setiawan, E. (2014). Analisis sikap konsumen terhadap produk fashion lokal dan impor. Jurnal Economia, 10(1), 38-47.

Sumarwan, Ujang. (2015). Perilaku Konsumen. Edisi kedua. Kota Bogor: Penerbit Ghalia Indonesia.

Sustina. (2003). Perilaku Konsumen Dan Komunikasi Pemasaran, Bandung: PT. Remaja Rosdakarya,

Tjiptono, Fandy. (2011). Manajemen dan Strategi Merek. Yogyakarta: Penerbit Andi.

\section{Lampiran 1. BUTIR PERNYATAAN ANGKET}

\begin{tabular}{|c|c|c|}
\hline Variabel & Butir Pernyataan & Sumber \\
\hline Sales & Erigo selalu memiliki program diskon di Shopee setiap bulannya. & (Bhatti, 2018), (Chang, \\
\hline \multirow[t]{5}{*}{ Promotion } & $\begin{array}{l}\text { Erigo memberikan diskon lebih besar dibandingkan dengan brand } \\
\text { pesaing. }\end{array}$ & $\begin{array}{l}\text { 2017), (Rosaliana, 2018), } \\
\text { (Cipto, 2020). }\end{array}$ \\
\hline & $\begin{array}{l}\text { Erigo selalu berkolaborasi dengan Shopee untuk memberikan } \\
\text { gratis ongkir. }\end{array}$ & \\
\hline & $\begin{array}{l}\text { Saya bersedia membayar produk ramah lingkungan dengan harga } \\
\text { mahal. }\end{array}$ & \\
\hline & $\begin{array}{l}\text { Shopee mengadakan program cashback untuk minimum } \\
\text { pembelian pada produk Erigo. }\end{array}$ & \\
\hline & $\begin{array}{l}\text { Erigo sering memberikan kupon dalam promo buy } 1 \text { get } 1 \text { setiap } \\
\text { bulan. }\end{array}$ & \\
\hline \multirow[t]{12}{*}{ Brand Equity } & Saya dengan mudah mengingat logo Erigo. & (Gautam, 2018), \\
\hline & Saya dengan mudah mengingat nama produk Erigo. & (Samaraweera, 2018), \\
\hline & Saya sering melihat produk Erigo di beranda utama aplikasi & (Otero, 2018). \\
\hline & Saya lebih familiar dengan produk erigo dibanding produk brand & \\
\hline & lokal lain & \\
\hline & Saya mengetahui kualitas produk Erigo. & \\
\hline & Kualitas produk Erigo sesuai dengan harapan saya. & \\
\hline & $\begin{array}{l}\text { Erigo memiliki ciri khas produk dengan gaya berpakaian jalanan } \\
\text { atau "Streetwear Style" yang berbeda dengan produk pesaing. }\end{array}$ & \\
\hline & Erigo memiliki seri produk jaket "Sukajan" yang memiliki & \\
\hline & keunikan tersendiri dibandingkan dengan merek lainnya. & \\
\hline & Saya selalu merasa puas dengan produk Erigo yang saya gunakan. & \\
\hline & $\begin{array}{l}\text { Saya selalu mengunjungi official Erigo di Shopee setiap ada } \\
\text { produk keluaran terbaru. }\end{array}$ & \\
\hline \multirow{3}{*}{$\begin{array}{l}\text { Re-Purchase } \\
\text { Intention }\end{array}$} & Saya berencana untuk membeli kembali produk Erigo. & (Chang, 2017), (Rosaliana, \\
\hline & Saya merekomendasikan produk Erigo kepada keluarga, dan & 2018), (Cipto, 2020), \\
\hline & $\begin{array}{l}\text { Saya lebih memilih untuk membeli produk dari Erigo di samping } \\
\text { ada produk lain. }\end{array}$ & \\
\hline
\end{tabular}

Sumber: Data diolah (2020) 